\title{
Evaluation of TNF $\alpha$ expression in cattle experimentally infected by Trypanosoma vivax
}

Otavio Luiz Fidelis Junior ${ }^{[a]}$, Paulo Henrique Sampaio ${ }^{[a]}$, Luiz Ricardo Gonçalves ${ }^{[a]}$, Priscila Preve Pereirad ${ }^{[a]}$, Kayo José Garcia de Almeida Castilho Neto ${ }^{[a]}$, Inalda Angélica de Souza Ramos ${ }^{[a]}$, Marcos Rogério André[a], Rosangela Zacarias Machado[a], Fabiano Antonio Cadioli[a,b]

\footnotetext{
[a] Faculdade de Ciências Agrárias e Veterinárias, Universidade Estadual Paulista (UNESP), Jaboticabal, SP, Brazil

${ }^{[b]}$ Faculdade de Medicina Veterinária, Universidade Estadual Paulista (UNESP), Araçatuba, SP, Brazil
}

${ }^{*}$ Corresponding author

e-mail: otaluf@gmail.com

\section{Abstract}

Trypanosoma vivax infections in livestock have been occurring with increasing frequency all over the planet, however the disease still poorly studied and some aspects of its pathophysiology remain obscure. Knowledge of the immune response profile is important not only for understand the host-parasite relationship, but also for the development of new treatment strategies. TNF $\alpha$ is a proinflammatory cytokine produced predominantly by macrophages and is related to the innate immune response. The present study aimed to determine the variation of TNF $\alpha$ profile by RT-qPCR in cattle experimentally infected by T. vivax. Three Girolando cows (E1 to E3) experimentally infected with 2.0 x $10^{7}$ trypomastigotes of T. vivax, "Lins" isolate, were used. Three millilitres of whole blood were collected in 10\% EDTA solution for evaluation of TNF $\alpha$ profile and GAPDH expression (reference gene) on the day of inoculation (D0), on the day following inoculation (D1) and thereafter every seven days up to 119 days after infection (DAI). Samples were aliquoted in microtubes containing RNAlater ${ }^{\circledR}$ solution, according to manufacturer's recommendation and cryopreserved in $-80^{\circ} \mathrm{C}$ freezer, until the moment of use. For total RNA extraction the RiboPure ${ }^{\mathrm{TM}}$-Blood ${ }^{\circledR}$ commercial kit was used, following manufacturer's protocol. The concentration and quality of extracted RNA were evaluated by spectrophotometry (NanoDrop 2000 ${ }^{\circledR}$ ) and by Agilent 2100 Bioanalyser $^{\circledR}$, respectively, both according to manufacturer's instructions. An aliquot of the total RNA was converted into cDNA using GoScript $^{\mathrm{TM}}$ Reverse Transcription System ${ }^{\circledR}$, according to manufacturer's procedure. The RT-qPCR was performed as described by Puech et al. (2015). For samples relative quantification the equation proposed by Livack and Schmittgen (2001) was used. Each animal had its own profile of TNF $\alpha$ expression, the profile of animal E1 was - 1 (0DAI), 0.73 (1DAI), 0.40 (7DAI), 0.43 (14DAI), 0.40 (28DAI), 0.76 (35DAI), 0.65 (42DAI), 1.31 (49DAI), 0.62 (56DAI), 0.60 (63DAI), 0.84 (70DAI), 0.74 (77DAI), 1.27 (84DAI), 0.61 (91DAI), 
0.69 (98DAI), 0.65 (105DAI), 0.89 (112DAI) and 0.47 (119DAI) times expressed; the animal E2 was - 1 (0DAI), 1.72 (1DAI), 1.27 (7DAI), 1.45 (14DAI), 0.85 (28DAI), 0.92 (35DAI), 1.48 (42DAI), 1.71 (49DAI), 1.63 (56DAI), 1.17 (63DAI), 1.05 (70DAI), 1.31 (77DAI), 1.87 (84DAI), 2.11 (91DAI), 1.13 (98DAI), 1.80 (105DAI), 1.64 (112DAI) and 2.37 (119DAI) times expressed; and animal E3 was - 1 (0DAI), 0.53 (1DAI), 0.83 (7DAI), 0.33 (14DAI), 0.44 (28DAI), 0.51 (35DAI), 0.71 (42DAI), 0.51 (49DAI), 0.31 (56DAI), 0.55 (63DAI), 0.41 (70DAI), 0.47 (77DAI), 0.63 (84DAI), 0.30 (91DAI), 0.43 (98DAI), 0.74 (105DAI), 0.26 (112DAI) and 0.72 (119DAI) times expressed. Variant surface glycoproteins (VSGs) released by trypanosomes are probably responsible for the induction of $\mathrm{TNF} \alpha$ production, but the exact role of this cytokine during infection by parasites of the genus Trypanosoma sp. still controversial. More studies are needed to contribute to a better understanding and control of this disease. 